\title{
Epistemological limitations of Earth System science to confront the Anthropocene crisis
}

\begin{tabular}{|c|l|}
\hline Journal: & The Anthropocene Review \\
\hline Manuscript ID & ANR-20-0035.R1 \\
\hline Keywords: & $\begin{array}{l}\text { positivism, dialectics, natural laws, materialism, social production laws, } \\
\text { idealism, Marx }\end{array}$ \\
\hline & $\begin{array}{l}\text { Our current understanding of the Earth System has significantly } \\
\text { improved in recent years. As a result, the Anthropocene is seen as a } \\
\text { major planetary emergency not only for humans but for other living } \\
\text { organisms too. However, Earth System science lacks a proper integration } \\
\text { of the social or human side and the natural side of the Earth System into } \\
\text { an organic theoretical corpus. Without such an integration a } \\
\text { comprehensive understanding of the Earth System is not possible, and } \\
\text { the practical actions undertaken to face the Anthropocene crisis will only } \\
\text { alleviate some of its effects but the planetary emergency will keep } \\
\text { deepening. The epistemological reason underlying disagreement between } \\
\text { natural and social sciences is that Earth System scientists understand } \\
\text { the natural side of the Earth System and the Anthropocene from a } \\
\text { dialectic and materialist perspective, whereas they understand the social } \\
\text { side of the studied object from a positivist and idealist perspective. Such } \\
\text { a dualist approach hampers a proper understanding and the practical } \\
\text { actions aimed at transcending the planetary crisis. By consciously } \\
\text { adopting a dialectic and materialist epistemic paradigm under which both } \\
\text { natural and social realms are studied and understood, Earth System } \\
\text { scientists would be able to identify the internal contradictions of the } \\
\text { studied objects and, accordingly, to address the research in the suitable } \\
\text { directions. In this way, structural solutions and not merely conjunctural } \\
\text { measures to face the Anthropocene crisis could be formulated. }\end{array}$ \\
\hline Abstraction
\end{tabular}

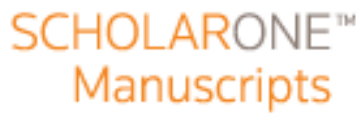




\title{
Epistemological limitations of Earth System science to confront the
}

\section{Anthropocene crisis}

\begin{abstract}
Our current understanding of the Earth System has significantly improved in recent years. As a result, the Anthropocene is seen as a major planetary emergency not only for humans but for other living organisms too. However, Earth System science lacks a proper integration of the social or human side and the natural side of the Earth System into an organic theoretical corpus. Without such an integration a comprehensive understanding of the Earth System is not possible, and the practical actions undertaken to face the Anthropocene crisis will only alleviate some of its effects but the planetary emergency will keep deepening. The epistemological reason underlying disagreement between natural and social sciences is that Earth System scientists understand the natural side of the Earth System and the Anthropocene from a dialectic and materialist perspective, whereas they understand the social side of the studied object from a positivist and idealist perspective. Such a dualist approach hampers a proper understanding and the practical actions aimed at transcending the planetary crisis. By consciously adopting a dialectic and materialist epistemic paradigm under which both natural and social realms are studied and understood,
\end{abstract}


Earth System scientists would be able to identify the internal contradictions of the studied objects and, accordingly, to address the research in the suitable directions. In this way, structural solutions and not merely conjunctural measures to face the Anthropocene crisis could be formulated.

\section{Keywords}

Positivism, idealism, dialectics, materialism, natural laws, social production laws, Marx

\section{Introduction}

The studies undertaken on the Anthropocene during the present century allow conceptualizing it as a planetary emergency affecting most of the terrestrial geospheres. These studies emphasize the need to deeply reconsider the current relationship between humans and the rest of the planet. A radical rethinking of our role on the planet has necessarily to involve the whole global society. Accordingly, most Anthropocene researchers from natural and social science disciplines claim to integrate social sciences/humanities and natural sciences into the Earth System science, aiming to build up a broader and more encompassing theoretical corpus capable of facing the Anthropocene crisis (Palsson et al., 2012; Mooney et al., 2013; Oldfield and Steffen, 2014, Guillaume, 
2014; Oldfield, 2018; Jouffray, 2020). However, many scientists from natural science disciplines regret the difficulties when dealing with social science theories due to the lack of an overall consensus on the topics studied and to the numerous and disperse approaches followed in social sciences, which hamper fluid communication and a proper understanding between natural and social science disciplines (Mooney et al., 2013; Oldfield, 2018).

This contribution investigates the epistemological nature of the main misunderstandings between the social and natural sciences. For this purpose, the formal differences between social and natural science disciplines are distinguished from those differences related to the fundamentals of the natural and social sciences. A review of current epistemic paradigms regarding social systems in general and the capitalist production mode in particular is also provided. As with most natural sciences, Earth System science takes a dialectic and materialist epistemic view in understanding the natural side of the Earth System and of the Anthropocene crisis. From the social side of the problem however, the epistemic view adopted turns into a positivist and idealist one, which is dominant in mainstream social sciences-economics, politics, philosophy, etc. In this way, the historical and concrete character of the Anthropocene is seen under two contrasted epistemic views and, as a result, a comprehensive understanding of the Anthropocene dilemma becomes impossible in the core of Earth System sciences. An objective and 
concrete understanding of the Anthropocene is necessary for any practical strategy aimed to transcend the planetary crisis and not just to merely alleviate its effects. This can only be achieved from a Marxian materialist and dialectic epistemic perspective.

\section{Science and scientific knowledge}

Scientific knowledge pursues comprehension of the concrete totality studied, that is, comprehension of the multiple and mutually interrelated determinations whose synthesis shape the concrete system which is the investigated object. Scientific understanding of a given system requires theoretical elaboration of the observed phenomena. That is, it requires the transformation of the empirical phenomena given to us by practice and experience into concrete concepts articulated within an organic theory capable of grasping the movement-i.e., the history — of the object in question. Scientific understanding means knowing the specific role of each determination in the configuration of the investigated system. It means knowing the history of the system, thereby roughly predicting the evolution of the system. From a methodological perspective, abstraction of concrete concepts by theoretical thought is a remarkably different process than abstracting generalities from the observed phenomena. Essentially, the first is deductive while the second is inductive, and both are necessary and complementary moments for any 
understanding of the concrete reality. Empirical abstractions by induction are required in the process of theoretical thought and have the descriptive role upon which theoretical deduction can be based. They are fixed as notions in every day practice and language through historical and cultural processes and they are critically examined in the course of scientific research.

The studied object is a material reality that exists outside of the human mind and regardless of the sort of theoretical conceptualizations about it. Comprehension of such a reality is necessarily mediated first, by sensory perception of phenomena and second, by human thought. It is for this reason that it is subject to the mechanisms of logic. Thirdly it is mediated by practice as the universal criteria of truth. The ability to operate a material transformation of reality deciphers to what extent a scientific understanding of a particular system is correct or not (Ilyenkov, 1982). Practice is the ultimate aim, being an end in itself beyond which no other end is possible. In the process of knowledge, the human interaction with reality, no matter whether it is social or natural, always faces to us as objective, and for this reason it can be scientifically known. Abstracting generalities via induction and theoretical elaboration by logical deduction are a means for the dynamic interaction with reality — they are 'vanishing moments' with regard to practice. However, whatever is the material transformation of reality, it always appears as an objective reality independent of 
the way in which it is perceived and thought. In a broad sense, rational thought is understood "as the ideal component of the real activity of social people transforming both external nature and themselves by labour" (Ilyenkov, 1977: 2). Labor is here defined as the practical activity able to transform reality. It is the human universal par excellence, with immanent teleological character that implicitly requires knowing the aims and means and adopting ethical decisions on the particular activity undertaken, as well as on the results obtained (Luckács, 1980). From an anthropological perspective, labor is the specific activity by which humans have evolved through history into a human social being.

Scientific knowledge is here understood as a social product carried out by a collective social being throughout history, in which individuals participate as active members. They, themselves, are determined by the structures of a given historical society, with a given historical scientific knowledge that they submit for critical examination over the course of their scientific research. A collective social being means that society is not an aggregate of individuals that interplay among themselves following their particular interests, where the State, or God acts as an abstract and independent regulatory body. This would be a sort of Hobbesian-Hegelian conception of society, which certainly corresponds to some historically determined kinds of society, but is in no way a human universal. Rather, society is here conceived as a social being in which individuals evolve collectively, 
in other words, a social being that evolves with and because of the evolution of individuals and vice versa. In this regard, science can be conceptualized as the never-ending activity of the social being aimed at understanding the concrete reality and to allow a practical interaction and transformation. Paraphrasing Samuel Beckett's famous quote, when performing scientific activity, humans "fail, fail again, fail better". It is beyond the scope of this contribution to provide a detailed analysis of human understanding throughout history, involving religious forms, crude materialism and empiricism, ancient and Hegelian dialectics, positivism, postmodern relativism, and so on, which would certainly reveal a non-linear progress of scientific knowledge. Yet, it seems quite plausible to posit a gross evolution of human knowledge from an abstract and idealist understanding based on myths and Gods to a more concrete and materialist-based understanding of reality that allows a more practical and particular interaction with it.

\section{Natural and social science disciplines}

Splitting scientific knowledge into natural and social science disciplines was a formal division promoted by neo-Kantian philosophers in the XIX ${ }^{\text {th }}$ century (Ilyenkov, 1982), partly in response to Hegelian philosophy. Before such rupture most philosophers and thinkers, including those in earlier modernity (Steno, Leibniz, Petty, Descartes, etc.), had a 
broader and all-encompassing approach that did not make such a sharp distinction between the social and natural sciences. The most relevant formal difference between the fields of social and natural sciences is related to the time-scales over which the respective studied objects evolve compared to how the time-scales at which the theories on those objects do.

The object studied by natural sciences does not usually change in the course of the historical development of its theoretical understanding. In other words, the time-scale of the evolution of the studied object occurs over such orders of magnitude that it can be neglected with respect to the time-scale at which the different theories on the object evolve. This is the case for physics, biology, geology, and most of the natural science disciplines. The theoretical understanding of the cosmos has significantly evolved from geocentrism, heliocentrism, gravitational physics and relativity, but the object studied has remained the same in the course of this evolution. Similarly, a theoretical understanding of the origin of life and the evolution of species has changed since Lamarck, Darwin, Oparin, and to present genetic theory, but the object studied is the same for all of them. In these cases, old theories are generally seen as simple and abstract expressions of the theoretical understanding of the object, while recent theories are seen as more complete and concrete, the whole theoretical development corresponding to the "failing, failing again, failing better" process mentioned above. For example, Alfred Wegener's continental drift is a 
simple and abstract theory with respect to the more complete and concrete plate tectonics. Things are different for social science disciplines. Here, the evolution of the studied system occurs on about the same time-scale as the evolution of the theories on it. In these cases, the historical unfolding of the theories roughly reflects the historical development of the studied object (Ilyenkov, 1982). Moreover, the different theories throughout history provide different forms of dynamic interaction with the system that may interfere with its development. This may modify the phenomenal forms in which the studied object is shown and, accordingly, may modify the inductive abstraction of generalities inferred from empirical and sensory perception. To illustrate the mutual interaction between the development of the studied system and the development of the theoretical understanding in social science disciplines, a crude analogy with Heisenberg's uncertainty principle could be made which, colloquially affirms that the empirical determination of two variables interferes with the state of these variables. For example, a theoretical understanding of social production modes have grossly evolved contemporaneously alongside the practical interaction with Nature, leading to its material transformation and to the different production modes observed over human history. Hence, Aristotle could not have a concrete concept of abstract labor because at his time abstract labor as a social average did not exist. In contrast, David Ricardo was able to understand abstract labor as the substance of value 
because abstract labor as a social average constitutes the social reality of capitalist production (Ilyenkov, 1982).

The formal differences between the natural and social sciences explain why naturalists can see themselves as external observers to the studied system, whereas social scientists cannot. Although a deeper understanding of the reality of natural systems usually reveals that the activity of scientific research does interfere with the studied system, in most cases and for practical purposes, such activity can be neglected. Hence, Heisenberg's principle is not restricted to particle physics, but it applies to Newtonian physics too, or if we consider measuring the temperature of the ocean, it implies a mutual interaction, a change of both water temperature and thermometer temperature (Piedra Arencibia, 2016). In these cases, as in the scientific research of the history of the Earth, the history of life and the history of the cosmos, humans can neglect the interference of their activity on the objects they study, although such interference does, obviously, exist. However, when dealing with social systems, an approach that places us as external observers to the system is no longer possible because the practical interaction with the system strongly modifies the studied object and its scientific understanding. For example, humans can change and have changed their modes of social organization throughout history, hence, understanding social production modes and the practical transformation of production modes are mutually 
conditioned.

\section{Natural laws and social production laws}

There is a deeper — not just formal—difference between the natural and social sciences. Natural systems do not develop under any teleological design that determines the goals to be achieved and the means needed to achieve them. Rather, the evolution or history of natural systems is shaped by the interaction of multiple determinations that are mutually concatenated in a concrete way and, for this reason, they can be objectively known. Understanding the system means knowing the specific interplay of each determination with regard to the network of determinations that shape the object being studied. That is, it means understanding why and how a determination has a concrete role and not any other in a particular system. For example, in the atomic system each particle is in a particular relation with other particles and only this relation is possible within the limits of the system. Similarly, in the cellular system, in the plate tectonics system, each element is in a concrete relation with other elements of the system too. That is why deterministic laws describing the interactions of the elements forming the object - the history of the systemcan be formulated. Therefore, the theoretical understanding of Nature based on deductive logic, if correct, reveals a number of deterministic laws and principles that are compulsory 
within the limits of the studied system. For example, Newton's law of gravitation for macroscopic bodies, Heisenberg principle for atomic particles, genetic laws for living beings, Steno's law of superposition for sedimentary strata, etc. Humans are always subject to these laws regardless of the kind of practical interaction with the system and regardless of the way in which the system is thought to be. Again, practice is always the criteria that validates whether a theory is correct or not. For example, nuclear energy and nuclear weapons validate particle physics as a correct theory and genetically modified organisms validate modern genetics as roughly correct too. Note that such practical validation of theories does not imply any ethical position on the topics involved, nor does it have any immanent mandatory requirement. That is, the scientific understanding of particle physics does not mean, necessarily, that the atomic bomb has to be made, nor does the scientific knowledge of genetic laws mean that living organisms must be genetically modified. Here, concrete ethical decisions are possible precisely because the scientific theories are roughly correct. Actually, ethical decisions permeate the whole scientific research process, mainly in the form of the ethics and morals currently considered to be standards for a given society. For this reason, scientific and technical knowledge is not neutral (Piedra Arencibia, 2018). In any case, natural laws are always mandatory and, say, if humans want to fly with airplanes they have to strictly consider the law of gravitation. 
Social systems are subjected to the laws and principles of Nature too, since humans have to necessarily operate within the natural limits and they "can work only as Nature does, that is by changing the form of matter" (Marx, 2015: 31). Hence, humans have to follow natural laws in their practical interaction with Nature. However, social systems can be changed by conscious and unconscious human action and, therefore the specific rules and principles of a given type of society can be substituted by others. This usually implies the profound transformation of a society into a new one, affecting the form in which social systems produce and reproduce themselves according to their particular features and the form in which the social reality is perceived and understood. For example, the form in which hunter-gatherer societies reproduced themselves - including both the material and the ideal forms of social reproduction - is completely different from the form in which slave societies did it, which in turn is completely different from the particular form of feudal societies, and different again from that of the capitalist society. All of them, however, share labor as a universal concrete concept that mediates between Nature and humans and without which no kind of social system is possible. Presently, humans produce themselves as a historically complex social being based on their practical interaction with Nature through labor. Therefore, the key difference between natural and social systems, involving practical activity, epistemology and ethics, is that social systems and their 
corresponding laws can be transcended whereas natural systems and natural laws cannot. Because the capitalist society is the typical case of an autonomous social system spontaneously developed on the basis of commodified interpersonal relationships that are not subjected to a previous subjective design, deterministic laws similar to those of natural systems can be discovered and describe the dynamics of the system. To this end, however, a proper epistemic paradigm is necessary, otherwise the laws of capitalist production will not be revealed.

\section{Epistemic paradigms of capitalist society}

Capitalism is the first global society in human history, and it involves not just the material production of goods and services but the ideal production of notions, concepts and theories too. Material production and the production of ideas are necessary and inseparable moments for any social organization to reproduce itself according to its own foundations. Traditionally, there have been two contrasted epistemological approaches to understanding capitalism in particular and social production modes in general.

\section{Positivism and idealism}

From a positivist perspective, knowledge is understood as performed by individuals 
isolated from social reality with regard to the process of knowledge. It is an atomist view by which social knowledge is seen as an aggregation of individual contributions.

Individuals conduct inductive abstractions of generalities from their empirical and sensory perceptions, and concepts are the verbal forms (the terms) describing the common features perceived in the studied object. Hence, positivism does not distinguish notions - the forms of knowledge obtained by abstracting generalities from the empirical and sensory perceptions - from concepts - the forms of knowledge implying theoretical elaborations and abstractions by deduction — or, if so the distinction has only a formal character. Moreover, from a positivist perspective, there is no difference between thought and language, between the logic forms and the laws of thought and their symbolic expression in languages. For example, the neopositivist verification principle states that a scientific theory is correct if it is in formal agreement with the empirical data observed. The main logic principle underlying positivism is that of non-contradiction, which prescribes that although reality appears as contradictory, scientific theories can not have internal contradictions.

Mainstream social theories are based on formal or positivist logic. This means that the object studied - in our case, the capitalist mode, but in general, any social production mode - is not seen as a concrete totality shaped by the interaction of multiple 
determinations nor is it considered to be a dynamic object that results from evolution through an historical process. Rather, it is considered as a puzzled object composed of separated departments, which can be approached independently and whose aggregation encompasses the studied system. Eventually, the interactions among those departmentsfor example, education, economics, law, among others - will be highlighted, but the capitalist society is not seen as a concrete totality that can be understood based on elementary concepts abstracted from reality whose internal unfolding arises in the different phenomenal forms shown by empirical perception. Note that an historiographical exposition of events, that is, of the phenomenal expressions of the social system, cannot reveal their internal connections. Only the unfolding of the fundamental principles immanent to the system may provide a true history - the course of the development — of the system. Typically, a positivist approach proceeds by inductive abstraction of generalities from the observed phenomena and from the interconnections between already established notions and analytical categories. From there, one develops a formal deduction leading to formally consistent theories. The best case of a social scientific discipline driven by a positivist understanding of the studied reality is that of economics, but others are Malthusian and Neomalthusian demographic studies and Scientometrics.

The object studied by economics is the material production of the goods and 
services that all societies need to produce in order to reproduce themselves based on their particular characteristics. In the capitalist mode, production is not designed according to a previously conceived plan aimed to evaluate the needs of the society and the means and processes that are necessary to satisfy these needs. Rather, production is, above all else, commodity production, and it is driven by the profit inherently contained in any commodity. Based on this, producers - capitalists - find their position in the productive process of society and obtain a portion of the total profit produced. The spontaneous and non-planned interaction of individuals in the capitalist mode has been explicitly acknowledged by classical political economists such as Adam Smith with his well known 'invisible hand market', by the Austrian school's economists (von Misses, Hayek, etc.) who acknowledge the system of prices as a spontaneous mechanism that provides information to individual capitalists for their investment strategies and the formation of prices as an aleatory process, and, actually, it is recognized by all economists regardless of the school to which they ascribe. Time series of stock market values have been mathematically modeled by polynomial fit and other statistic techniques to provide investment tools for financial capitalists (Hendry, 2004). This is a clear example of the spontaneous and uncontrolled character of market prices, which are formed as a result of aggregated individual actions unconsciously exerted with regard to a comprehensive understanding of the economic 
system. For this reason, not only a system of market prices is needed, but mathematical tools aimed to navigate within this system as well. The example illustrates the positivist approach that underleies mainstream economics and, accordingly, the misunderstanding of capitalist fundamentals.

From a positivist perspective, the capitalist mode is conceived ahistorically as an absolute production mode, and not as an organic system that resulted from the internal development of fundamental elements, which constitute the essentials of the system and whose unfolding reveals the empirical phenomena observed and the history of the system. Here, the connections between the phenomenal forms (prices, profit, rent) and the essential concepts underlying such forms (commodity, labor, value) are not investigated. As a result, the system is not studied as an organic whole, but only the phenomena obtained by sensory perception are considered in order to articulate a formally consistent theory that ends up becoming a tautology, usually based on argumentative fallacies. In this way the system studied is not subjected to critical research but, on the contrary, it is formally legitimized. For example, the Austrian school endorses the need for a 'free' market and the formation of aleatory prices by assuming that production can only be organized based on aggregated individual actions driven by profit. That is, an historical form of social production and its corresponding social being is taken as absolute and, according to this premise, the 
characteristic interaction of individuals in terms of economy under such an historical form is given as an argument for the institutional expression of this interaction, namely, market prices (Cockshott and Nieto, 2017).

The approach of mainstream economics has a straightforward corollary: the materialism underlying the scientific knowledge of the capitalist mode of production is a positivist-based materialism and, therefore, it results in an idealist-based understanding of this particular production mode. Accordingly, the scientific understanding of this social system is reduced to a formal explanation that absolutizes the capitalist social being and the phenomenal forms of the capitalist production mode. In practice, this means that objective knowledge of the studied system becomes impossible and the only option is to navigate within the system with the help of spontaneous and uncontrolled social mechanisms. In this way, the fundamental contradictions of this particular social system—recurrent economic crises, unequal wealth distribution, and the Anthropocene crisis, among many othersremain unexplained and unsolved. All mainstream economic schools-marginalist, Neoclassical, Keynesian and Neokeynesian, Ricardian and Neoricardian, etc.—-share a common background of a subjective theory of value, implying that value is an individual sensory perception that cannot be objectively known, and only a formal, mathematical understanding of value forms(rent, profit, capital) is possible. The differences between 
mainstream economic schools are therefore just formal differences with regard to the subjective perception of value. As a result, an empirical phenomena of capitalist production such as the periodic economic crises is invariably attributed to the aggregation of bad individual decisions, but the immanent relationship of such crisis to the essentials of the production mode is never investigated. In summary, the positivist materialism of mainstream economics reveals the true idealist character underlying its epistemic approach.

\section{Dialectics and materialism}

An opposed epistemic view to positivism is dialectical materialism. Here, notions are seen as social rather than individual. Notions are fixed and expressed in language through historical and social processes and not as a result of perceptions and abstractions of individuals isolated from society, with regard to the process of knowledge. Rather, individuals come to historical social systems with already fixed notions and face them as an objective reality, which has to be individually apprehended and appropriated. In this view, thought is seen as the particular mode of the ideal activity of the social being as reflected in individuals. From a dialectic and materialist perspective, notions are fixed in culture and they are distinct from concepts; that is to say, the necessary theoretical elaboration of notions by logical deduction in thought, which have a symbolic expression in verbal 
language, mathematics, music, etc. Both notions and concepts must be critically reviewed in rigorous scientific research based on dialectics and materialism.

Marx's Capital constitutes the best example of a materialist and dialectic approach consciously and systematically applied to the understanding of a social system: the capitalist mode of production. In other words, Marx's Capital is a practical exercise of a dialectic and materialist epistemic view aimed at understanding a concrete mode of social production (Ilyenkov, 1982). However, most of the so called Western Marxism has not properly understood the materialist dialectics of Marx's Capital because a positivist and idealist epistemic conception is dominant in western countries. The 'official' philosophy during Stalinism and later on, was also driven by a positivist and idealist approach, which deformed the Marxian dialectical materialism into the so called DIAMAT (DIAlectical MATerialism). For these reasons, and after the collapse of Soviet-style economies, Marxian dialectical materialism has not been well received in western culture. Nevertheless, Marxian materialist dialectics attained the highest development in the Soviet Union during the $60 \mathrm{~s}$ and $70 \mathrm{~s}$ of the last century, with philosophers such as Evald Vasilievich Ilyenkov and many others who still remain poorly known. As pointed out by Chukhrov (2013), there is a remarkable epistemological gap between western culture and 'unofficial' PostStalinism Soviet culture that hinders a fluid dialogue. Such an epistemological gap is 
ultimately based on two contrasted epistemic views, a positivist and idealist understanding of social systems in the west, and a materialist dialectics one in the former Soviet east.

In Marx's Capital, the capitalist society is investigated as an organic historical system by unfolding the internal contradiction of the system's fundamental element: the commodity. By developing the internal contradiction of commodities, Marx is able to deduce value as the historical form of labor under the capitalist mode, money as a phenomenal form of value, capital as value that valorizes with the appropriation of the surplus value exerted by the labor force and, for this reason, capital as the fundamental social relationship of capitalist society. The phenomenal forms of value (salary, rent, profit, interest) are logically deduced in Marx's Capital by sequentially unfolding the contradictions of analytical categories derived from the practice of capitalist production, starting with commodity as the primary element. Here, every abstracted concrete concept accounts for the necessary conditions of existence of any particular phenomenal form that is empirically perceived in relation to the rest of the phenomena being studied. In turn, every abstracted concrete concept is the necessary consequence of the existence of the rest of phenomena. In Marx's dialectic and materialist understanding of the capitalist mode, profit is a value form, it is both a consequence of value and a prerequisite of value. The result of Marx's research is a theoretical corpus in which abstract and simple categories are 
dialectically connected to complex and concrete categories, allowing to understand not only the material production but also the ideal production, that is, how the ideal forms are settled in the culture and language of bourgeois society. Such a concrete interrelation of the multiple determinations shaping the particular studied object cannot be obtained by inductive abstraction of generalities of phenomena. It can only be accomplished by a deductive-logic process in which inductive abstraction is a necessary vanishing moment. This means that the concept of value cannot be obtained by abstracting generalities of the value forms, but rather, by unfolding contradictions by logical deduction, starting with the fundamental element of the system, the commodity. Only this method can provide the concept of value and its concrete relations with the value forms. The epistemological method followed by Marx in Capital is known as the ascent from the abstract to the concrete and it allows a scientific understanding of the capitalist concrete totality and its multiple determinations (Ilyenkov, 1982).

From an historiographical perspective, Marx benefited from the modern materialist tradition (Locke, Descartes, Berkeley, etc.), which he reviewed critically by examining Feuerbach's materialism. Marx benefited from the modern dialectic tradition that started with Spinoza and culminated with Hegel, which he also critically reviewed . In this way, he was able to go beyond the classic political economists (Petty, Smith, Ricardo) in the 
scientific understanding of the capitalist mode. Classic political economy attained its highest development with Ricardo. However, he failed (for a number of reasons) in trying to build up a theoretical corpus that was aimed to organically understand the fundamentals of capitalist production. First, he conceived of the capitalist production as absolute and not as an historically determined production mode. Second, he was not able to identify the primary element—namely, the commodity—from which unfold all the phenomenal forms of the production mode. Although Ricardo correctly distinguished concepts as concrete theoretical abstractions from notions fixed in language, he imagined an immediate correspondence between value and value forms, that is, a non-contradictory correspondence between value and profit, for example. As a result, he pretended to find value by abstracting it from the generalities of the value forms (profit, salary, rent) and, as long as it is not possible, he concluded that the unfolding of value into value forms occurs only in thought and not in reality. In summary, Ricardo's efforts to deduce value from value forms were based on formal deduction, revealing the positivist and idealist nature of his approach (Ilyenkov, 1982).

Nevertheless, Ricardo's efforts to understand the relations between the universal concrete concept of value and its phenomenal expressions were much more scientific than most of the mainstream economists that followed him. At least, he correctly identified 
abstract labor as the substance of value, and production as the key moment of capital valorization, whereas most mainstream economists undertake a scholastic legitimization of the capitalist mode usually based on vulgar empiricism. For example, Piketty's bestseller shows impressive data on the uneven wealth distribution in capitalism but it is not able to connect it to the structural foundations of capitalist production (Piketty, 2017). As a result, his proposal is merely reduced to taxing the profits capital such as to redistribute wealth. However, this leaves untouched the capital reproduction status quo, which includes the Anthropocene crisis. Such a simple proposal does not obviously need a scientific understanding of the production mode and does not solve the structural problem of capitalist production. Besides, the math developed by Piketty relies on Neoclassical argumentative fallacies aimed to show that the profit rate of capital does not descend during capitalist production and, therefore, that the reproduction of capital is able to provide an 'infinite' wealth, which, 'unfortunately', is wrongly distributed. Maito (2014) uses the same database as Piketty to show that the rate of profit descends when it is properly estimated. Based on an opposed epistemic paradigm to Piketty, Marx was able to show that uneven wealth distribution is a must of capitalist production. Marx was not describing empirical data like Piketty, but he was based on logical deduction following the law of capitalist accumulation, which was formulated by himself and has this concise expression: 
"Accumulation of wealth at one pole is, therefore, at the same time accumulation of misery, agony of toil slavery, ignorance, brutality, mental degradation, at the opposite pole, i.e., on the side of the class that produces its own product in the form of capital" (Marx, 2015: 345). According to Marx's dialectics, uneven wealth distribution is a necessity of capital accumulation that any tax can cancel.

\section{The concept of the Anthropocene}

From an epistemological perspective, the Anthropocene is a concrete concept, or concrete abstraction, shaped by the synthesis of multiple determinations interacting from both the natural and social realms. The concept of the Anthropocene as a planetary crisis is obtained by theoretical abstraction and logical deduction of observed phenomena obtained by sensory perception and empirical experience. The empirical data collected on the Anthropocene crisis by Earth System scientists is extremely clear: the current planetary crisis is human-induced, it is historically restricted to, at most, the last 200-300 years and the crisis itself as shown by the ensemble of empirical indicators that have deepened during this historical period, regardless of if a particular indicator shows a partial recovery. Hence, the Anthropocene reveals that human action exerted through a particular and historically determined social system, that is, the capitalist mode of social production, is the main 
determinant in the concrete concept of this planetary crisis (Chen, 2017; Foster, 2017; Soriano, 2018).

The crisis of the Anthropocene has dramatically changed the Neokantian traditional break between the natural and social sciences. The Anthropocene, as a concept that results from the human interaction with the planet under an historical mode of social organization, above all reveals the inadequacy of the traditional dualist approach based on the separation of natural and social sciences. Here, everything is so closely interrelated that such a dualist approach is methodologically incorrect and, besides, the close interaction between natural and social processes cannot be fully untangled if natural and social realms are treated separately. Second, the Anthropocene reveals that scientists can no longer approach the Earth System as external observers, as has been usually done in the natural sciences. Finally, it reveals that the practical activity aimed at transcending the planetary crisis depends on a correct understanding of the social and natural determinations of the crisis. That is, if the interrelations between natural and social determinations are not properly conceptualized under a suitable epistemic paradigm, the crisis will deepen and humans will not be able to transcend it.

\section{The Earth System science approach to the Anthropocene}


Natural and social science disciplines are formally different regarding the time-scales over which the studied objects and the theories about them evolve. In addition, natural systems and natural laws cannot be substituted, while social systems and their laws can be changed by others provided a suitable human action is followed. For these reasons, and in particular after the Neokantian break-up between the natural and social sciences, philosophers and thinkers have questioned whether it is possible to undertake a theoretical and objective understanding of social systems based on logical deduction, as is usually undertaken for natural systems. When Earth System scientists from natural disciplines approach social science theories in the context of the Anthropocene crisis they have to deal, perhaps inadvertently, with this epistemological question. The epistemological perspective adopted by Earth System scientists when dealing with this question is crucial to a successful understanding of the Anthropocene dilemma.

Due to the immanent relation of the Anthropocene crisis with capitalism, a scientific understanding of the capitalist mode of production is unavoidable in order to properly face the planetary crisis underlying the concept of the Anthropocene. Otherwise, the practical actions undertaken will regrettably only alleviate some of the effects of the planetary emergency, but they will not be able to transcend it. When naturalists incorporate social science theories into the corpus of Earth System science they do not critically reexamine 
these theories, including those of the capitalist mode of production. Rather, they form their ideal conceptions on the social issues following the current and dominant epistemic paradigms. This is quite understandable since "Not every artist has a well-developed concept of art, by any means, although he may create magnificent works of art. The present author is not ashamed to admit that he has a rather vague notion of the atom, as compared to a physicist. But it is not every physicist that has a concept of the concept" (Ilyenkov, 1982: Concrete Unity as Unity of Opposites). Regarding the social component that needs to be considered together with the natural component in order to have a comprehensive understanding of the Anthropocene crisis, the epistemological view adopted in Earth System science is that of mainstream economics, philosophy, politics, and so on. However, a positive solution to the crisis demands a critical reexamination of theories in most social science disciplines, and in particular of theories regarding the capitalist mode of production because the ultimate cause of the crisis is the concrete relation of humans with Nature under this production mode. Neither scientists from natural disciplines nor scientists from mainstream social disciplines involved in Earth System science have undertaken such a critical review and, therefore, they are not equipped with the suitable epistemological background demanded by the Anthropocene crisis.

Understanding Nature implicitly acknowledges that Nature is an objective material 
reality outside of the human mind and independent of the way in which it is thought and known. Earth System science is not an exception. Understanding the Earth as a concrete entity in which the particular interaction of multiple determinations are characterized, is always an unfinished process that allows knowing the history and the dynamics of the Earth System. Such a view would have been impossible from an idealist-based perspective, where it lacks any concrete internal articulation, and only individuals are able to confer a structure upon Nature by means of thought and language. In other words, from an idealist perspective, Nature is deprived of any causal concatenation or history, which is only an attribute of human thought and language (Piedra Arencibia, 2017). On the contrary, from a materialist perspective, a materialist-based approach to Nature is a demand of the object studied. It is an epistemological requirement based on the fact that Nature is an objective and material reality. Earth System scientists proceed, whether they are aware or not, according to a materialist-based epistemic view when dealing with the natural component of the Anthropocene crisis.

Nature is dialectical too, and the dialectics of Nature is not merely a theoretical construct but a construct that is only possible because Nature is inherently so. Otherwise, how is it possible to 'construct' dialectics if it is not yet in the studied object, which is the ultimate source of any empirical perception? The origin of life and the evolution of species 
are examples of dialectics in Nature. Organic molecules, which are the basis for the origin of life on Earth, evolve as a 'negation of' or 'in contradiction to' inorganic molecules and constitute a new structure of matter with new and particular laws than the laws of the inorganic realm. Contradiction is the driving mechanism of the evolution of species too, in which differences among individuals within a species evolve into differences among species, that is, contradiction of individuals with respect to an average becomes the differentiation of a new average (Levins and Lewontin, 2009). The internal constitution of matter from the Higgs boson to the classic atomic particles and to molecules is the result of an evolution based on contradictions of the constitutive elements, usually expressed as opposed electric charges, but not only. Actually, particle physics is based on the contradiction principle as the driving mechanism by which matter is constituted and differentiated. The well known wave-corpuscle duality is the example of a contradiction defining both the identity and the difference of matter. Practical application of the wavecorpuscle duality in electron microscopes shows that the contradiction is real, and for this reason it is seen as a logic contradiction in thought — it is expressed in language too. The elliptical orbit of planets and satellites is defined as the unit of two opposite movements, by which planets get closer to and move away from a larger planet or star. Natural systems are historical. They evolve autonomously by overcoming successive contradictions, and at any 
step of the evolution the newly established conditions assume in their core the structural laws and the evolution of previous stages. To borrow a term from evolutionary biology, the evolution of natural systems occurs in homeostasis and, hence, inorganic matter evolves within the structure of organic matter, cellular elements evolve within the structure of more complex living organisms, and so on. As shown by the Anthropocene crisis, the whole Earth System is now evolving within the structure and laws of the capitalist production mode.

Contradictions are not merely logic constructs of thought due to failures in the subjective perception of reality or due to failures in the subjective theoretical elaboration of the empirical perception, and they can not be solved by formally refining theories as claimed by formal logic. Rather, they reflect the real contradictions of the object, and both the real contradictions and the logic contradictions are necessarily and formally expressed in language. For this reason it is not possible to make an a priori distinction- - based on verbal expression - between a real contradiction and speculative contradictions that are not related to reality or are useless in terms of the practical activity (Iliénkov, 1999). Only an analysis of the content of the verbally expressed language as related to the practical interaction with the material reality allows a discrimination between real and speculative contradictions. Heisenberg's uncertainty principle may help to illustrate the real nature of 
contradictions. Essentially, it states that the empirical perception of an object based on its perturbation turns out to be the very impossibility of its perception. Newtonian mechanics had inadvertently overcome this paradox by neglecting the effect of the perturbation in the object and particle physics has pragmatically overcome it by probabilistic means, which is a formal solution. In any case, the contradiction stated by the Heisenberg principle is not canceled because it is a real contradiction.

However, most naturalists are unaware of the dialectic constitution of Nature and they are also unaware of the dialectic and materialist epistemic view they are following in the scientific understanding of Nature. Naturalists are forced to spontaneously undertake this epistemic view because the studied object is a material and dialectical reality. The epistemic approach to Nature has to be consistent with the structure of Nature, otherwise knowledge is incomplete. In other words, the dialectics of Nature reflects in human thought as dialectical logic and as a dialectic and materialist understanding. Yet, as pointed out by Piedra Arencibia (2017) paraphrasing Marx, naturalists 'do not know what they do but they do it'. This is the key difference between Marx's approach to the study of social production modes and naturalists' approach to the study of Nature. Marx consciously adopted a materialist and dialectic view to understand capitalism, whereas naturalists have unconsciously adopted this epistemic view to understand Nature. Nevertheless, conscious 
Marxian dialectics and unconscious naturalists' dialectics are the correct approaches to understand the studied objects, as shown by the predictive character achieved by their corresponding scientific corpus. For example, astronomical tuning of deep sea sediments allows not only to calibrate the time scale of chronostratigraphic successions of the geological record but also to predict the cyclic stratigraphy of future successions as long as similar boundary conditions prevail. Similarly, the law of the tendency of the rate of profit to fall predicts the long term evolution of capitalist production and has been empirically confirmed more than a century after Marx’s logical deduction.

Although it may sound paradoxical, the Anthropocene crisis is the empirical evidence that humans are following the correct path with regard to understanding the concrete functioning of Nature. The Anthropocene shows that the materialist and dialectic view of Nature is roughly correct because it reveals the true internal articulation and history of Nature. In other words, the inner structure of Nature is dialectic and material and for this reason only a materialist and dialectic approach is able to reveal such an internal configuration, which includes the present planetary crisis. In a nutshell, humans are nothing else than an evolution of matter; they are the thinking body of Nature and thought is an attribute of matter (Iliénkov and Naúmienko, 2016). That is why humans in the capitalist production mode have been able to subsume natural laws under capital reproduction laws. 
The concept of the Anthropocene reveals the ultimate contradiction of the capitalist production mode: the contradiction of capital reproduction with Nature and with humans as the thinking body of Nature.

Earth System science inadvertently proceeds according to a materialist and dialectic view with regard to understanding not only the present day configuration of Earth but also the history of the Earth. That is why a more concrete and complete knowledge of the multiple determinations and their mutual relations that shape the Earth System is possible. Consider the evolution of the Bretherton diagram or the Geologic Time Scale from their initial configurations in the last century up to the present day. Overall, they show the ongoing process of a more complete and concrete understanding of Earth. Unfortunately, this is only true for the 'natural side' of the studied object but not for the 'social or human side'. With regard to the social aspect of the Earth System and of the ongoing Anthropocene crisis, Earth System scientists conduct themselves under a positivist and idealist view, and as a result, a scientific integration of humans and their social production modes into the Earth System science becomes impossible. According to this dichotomic epistemic approach, Earth System science promotes a sort of planet stewardship to manage the planetary crisis that is based on a misunderstanding of the fundamentals of capitalist production, namely, a stewardship that is based on a positivist and idealist view of the 
relation between humans and Nature under this production mode. Ignorance of the socioeconomic laws of capital reproduction — the law of value, the law of capitalist accumulation, the law of the of the tendency of the rate of profit to fall, and so on-results in an idealistic conception, which imagines that humans control the production mode when it is in fact just the opposite; they are controlled by a production mode in which capital is the subject that dominates social reproduction (Soriano, 2018). Hence, imagined human agency to face the Anthropocene crisis is a fallacy within the limits of capital reproduction. The only possibility for an harmonious relation of humans and Nature is to get out of this production mode. Sustainability, corporate social responsibility, circular economy, ecological economics, degrowth, and, in general, all versions of green or human capitalism rely on several fallacious arguments. First, that the capitalist production mode is absolute and not historic. Second, that the reproduction of capital can be managed by a number of technical procedures usually based on crude positivism, implying the vulgar mathematization of society, which may deprive individuals of their human-social character. Third, that the social system can be properly managed as long as appropriate individuals awarded with some idealized humanism and skills are in charge. However, no matter whether he or she is in charge, the laws of capital reproduction will have to be followed and the differences in management will be only formalities. Although management may 
certainly alleviate some of the effects of the Anthropocene crisis it cannot change the course of the crisis. The different research projects and publications of the Future Earth network are examples of positivism and idealism regarding the social aspect of Anthropocene crisis. Some of the technical proposals therein may help to alleviate the crisis but the crisis itself will keep deepening. This has not been acknowledged within this network because a dialectic and materialist approach is lacking (see https://futureearth.org/). In summary, Earth System scientists' proposals to face the Anthropocene crisis are not based on a comprehensive and scientific approach to the Earth System encompassing humans and human societies. Such an approach has to necessarily rely on a dialectic and materialist epistemic view that is consciously adopted. Unfortunately, this is not the epistemic perspective of Earth System science.

\section{Conclusions}

Earth System scientists have unquestionably performed an invaluable contribution to our understanding of the Earth dynamics and of the ongoing planetary crisis. However, Earth System science has not been able to properly integrate the 'social side' and the 'natural side' of the Anthropocene crisis within a theoretical corpus based on a consistent epistemic view. Therefore, a comprehensive understanding of the Earth that includes humans and 
human societies and their role in the Anthropocene crisis is still lacking. The incomplete understanding of the Earth harms the proposals launched by Earth System scientists in order to face this planetary emergency. The main reason is epistemological in nature. While the Earth System is understood based on a materialist and dialectic epistemic view, which is correct, humans and human societies (the social being) are understood according to a positivist and idealist epistemic paradigm, which is incorrect. By consciously adopting a dialectic and materialist paradigm, Earth System scientists will be able to highlight the main contradictions in our current understanding of Nature, including both social and natural systems. In this way, scientific research can be addressed to solve contradictions and to build up a more complete and concrete understanding of the Earth System and the Anthropocene. Accordingly, practical actions aimed to transcend the planetary crisis and not merely to alleviate it, could be undertaken.

\section{Declaration of conflicting interest}

The author declares no potential conflicts of interest with respect to the research, authorship and publication of this article

\section{Acknowledgements}


I am grateful to Grant Buffet for English editing

\section{Funding}

This research has been partly funded by project AGAUR 2017 SGR 1022

\section{References}

Chen X (2017) The Ecological Crisis and the Logic of Capital. Leiden: Brill.

Chukhrov K (2013) Epistemological Gaps between the Former Soviet East and the "Democratic" West. E-flux journal 41: January. Available at: https://www.eflux.com/journal/41/60226/epistemological-gaps-between-the-former-soviet-eastand-the-democratic-west/

Cockshott P and Nieto M (2017) Cibercomunismo. Planificación económica, computadoras y democracia. Madrid: Trotta.

Foster JB (2017) The Earth-System Crisis and the Ecological Civilization: A Marxian View. International Critical Thought 7: 439-458.

Hendry DF (2004) The Nobel Memorial Prize for Clive W.J. Granger. The Scandinavian Journal of Economics 106: 187-213.

Guillaume B (2014) Vernadsky's philosophical legacy: A perspective from the 
Anthropocene. The Anthropocene Review 1: 137-146.

Ilyenkov E (1977) Dialectical Logic, Essays on its History and Theory. Moscow: Progress Publishers. Available at: https://www.marxists.org/archive/ilyenkov/works/essays/dialectical-logic.pdf Iliénkov E (1999) Sobre el papel de la contradicción en el conocimiento. Availble at: https://www.marxists.org/espanol/ilienkov/index.htm

Ilyenkov E (1982) Dialectics of the Abstract and the Concrete in Marx's Capital. Moscow: Progress Publishers. Available at: https://www.marxists.org/archive/ilyenkov/works/abstract/index.htm Iliénkov E and Naúmienko L (2016). Baruch Spinoza: Tres siglos de inmortalidad. Available at: https://elsudamericano.wordpress.com/2016/01/06/logica-dialecticaedwald-ilienkov

Jouffray J-B, Blasiak R, Norström AV, Österblom H and Nyström M (2020) The Blue Acceleration: The Trajectory of Human Expansion into the Ocean. One Earth 2: 4354.

Levins R and Lewontin R (1985) The Dialectical Biologist. London: Harvard University Press.

Lukács G (1980). The Ontology of Social Being. Talgarth: Merlin Press. 
Maito E (2014) Piketty versus Piketty. El Capital en el siglo XXI y la tendencia descendente de la tasa de ganancia. Revista de Economía Crítica 18: 250-264.

Marx K (2015) Capital, Volume I. Moscow: Progress Publishers. Available at: https://www.marxists.org/archive/marx/works/download/index.htm

Mooney HA, Duraiappa A and Larigauderie A. (2013). Evolution of natural and social science interactions in global change research programs. Proceedings of the National Academy of Sciences of the United States of America 110: 3665-3672.

Oldfield F (2018) A personal review of the book reviews. The Anthropocene Review 5: 97101.

Oldfield F and Steffen W (2014). Anthropogenic climate change and the nature of Earth System science. The Anthropocene Review 1: 70-75.

Palsson G, Szerszynki B, Sörlin S, Marks J, Avril B, Crumley C, Hackmann H, Holm P, Ingram J, Kirman A, Pardo Buendía M and Weehuizen R (2012) Reconceptualizing the 'Anthropos' in the Anthropocene: Integrating social sciences and humanities in global environmental change research. Environmental science \& policy 28: 3-13.

Piedra Arencibia R (2016) La dialéctica categorial y las ciencias naturales. Reseña crítica de Proceso al azar. Horizontes y Raíces 4: 71-80.

Piedra Arencibia R (2017) Marxismo y dialéctica de la naturaleza. La Habana: Editorial de 
Ciencias Sociales.

Piedra Arencibia R (2018) El papel del trabajo en el desarrollo del pensamiento humano. HYBRIS. Revista de filosofía 9: 173-206.

Piketty T (2017) Capital in the Twenty-First Century. London: Harvard University Press, Soriano C (2018) The Anthropocene and the production and reproduction of capital. The Anthropocene Review 5: 202-213. 